\title{
Chemical Content of Drinking Water Consumed in Different Regions of Anatolia and Evaluation in terms of Medical Geology
}

\author{
Zeynep Ozdemir \\ Mersin University, Faculty of Engineering, Geological Engineering Department, Mersin, Turkey \\ Betul Coskun Onal(Corresponding author) \\ Mersin University, Faculty of Engineering, Geological Engineering Department, Mersin, Turkey \\ E-mail: cbetul86@gmail.com \\ Yavuz Yilmaz \\ Mersin University, Faculty of Engineering, Geological Engineering Department, Mersin, Turkey \\ Aykut Cakir \\ Mersin University, Faculty of Engineering, Geological Engineering Department, Mersin, Turkey \\ Ahmet Feyyat Demir \\ Mersin University, Faculty of Engineering, Geological Engineering Department, Mersin, Turkey \\ Gulan Karademir \\ Mersin University, Faculty of Engineering, Geological Engineering Department, Mersin, Turkey \\ Ibrahim Satis \\ Mersin University, Faculty of Engineering, Geological Engineering Department, Mersin, Turkey
}

\begin{abstract}
In this study 136 water samples used as drinking water in Balıkesir / Erdek, Mersin / KaraduvarDavultepe, Samsun / Merkez and Diyarbakır / Central regions located in different regions of Anatolia were evaluated. In addition to their drinkability characteristics, chemical and physical parameters were determined. Element and anion contents of drinking water samples taken from the regions determined by ICP-MS ( $B, \mathrm{Na}, \mathrm{Mg}, \mathrm{K}, \mathrm{Ca}, \mathrm{Cr}, \mathrm{Mn}, \mathrm{Ni}, \mathrm{Cu}, \mathrm{Zn}, \mathrm{As}, \mathrm{Cd}, \mathrm{Ba}, \mathrm{Pb}, \mathrm{Al}, \mathrm{Fe}, \mathrm{Se}, \mathrm{Mo}$ ) and by the ion chromatography $\left(\mathrm{F}^{-}, \mathrm{Cl}^{-}, \mathrm{NO}_{2}^{-}, \mathrm{NO}_{3}^{-}, \mathrm{Br}^{-}, \mathrm{SO}_{4}^{-2}, \mathrm{PO}_{4}^{-2}\right)$. Analysis results were evaluated in compared with TSE 266 standard, WHO (World Health Organization) and EPA (USD Environmental Protection Agency); Balıkesir/Erdek (B: 0.13, $\mathrm{Al}: 2.08, \mathrm{Fe}: 0.44, \mathrm{Mn}: 0.10, \mathrm{Cl}^{-}: 287.06, \mathrm{NO}_{2}{ }^{-}: 23.54, \mathrm{NO}_{3}: 179.41^{\prime}$, $\mathrm{Br}: 0.64, \mathrm{SO}_{4}^{-2}: 302.61 \mathrm{ppm}$ ), Mersin/Karaduvar-Davultepe (Mg: 130.30, Al: 0.24, As: 0.02, Na: 393.85, $\left.\mathrm{K}: 12.06, \mathrm{Cl}: 712.83, \mathrm{NO}_{2}: 1.85, \mathrm{NO}_{3}{ }^{-}: 479.11, \mathrm{Br}: 1.48 \mathrm{ppm}\right)$, Samsun/Merkez (B:0.21, $\mathrm{Mg}: 53.36$, $\mathrm{NO}_{2}^{-}: 1.06, \mathrm{NO}_{3}^{-}: 144.03, \mathrm{Br}: 0.07 \mathrm{ppm}$ ) and Diyarbakır/Merkez (B:0.02, $\mathrm{NO}_{2}^{-}: 8.72 \mathrm{ppm}$ ) The constant consumption of water, which contains these heavy metal and anions, especially showing anomalies, can cause various diseases in time. It is recommended to investigate the causes of the pollution (household waste, sea water mix, induced formation etc.) and take the necessary measures and controlled drinking of these waters.
\end{abstract}

Keywords: Water, Heavy metal, Anion, Medical Geology, Anatolia

DOI: $10.7176 / \mathrm{JSTR} / 5-5-13$

\section{Anadolu'nun Farklı Bölgelerinde Tüketilen İçme Sularının Kimyasal İçerikleri ve Tıbbi Jeoloji Açısından Değerlendirilmesi}




\section{$\ddot{\mathbf{O} z}$}

Anadolu'nun farklı bölgelerinde yer alan Balıkesir/Erdek, Mersin/Karaduvar-Davultepe, Samsun/Merkez ve Diyarbakır/Merkez bölgelerinde içme suyu olarak tüketilen toplam 136 adet su örneğinin kimyasal ve fiziksel parametreleri incelenerek içilebilirlik özellikleri araştırılmıştır. Bölgelerden alınan su örneklerinin element ve anyon içerikleri ICP-MS ( $B, N a, M g, K, C a, C r, M n, N i$, $\mathrm{Cu}, \mathrm{Zn}, \mathrm{As}, \mathrm{Cd}, \mathrm{Ba}, \mathrm{Pb}, \mathrm{Al}, \mathrm{Fe}, \mathrm{Se}, \mathrm{Mo}$ ) ve İyon Kromatografisi $\left(\mathrm{F}^{-}, \mathrm{Cl}^{-}, \mathrm{NO}_{2}^{-}, \mathrm{NO}_{3}^{-}, \mathrm{Br}^{-}, \mathrm{SO}_{4}^{-2}, \mathrm{PO}_{4}^{-2}\right)$ ile belirlenmiştir. Elde edilen analiz sonuçları TSE 266, WHO, EPA standartları ile karşılaştırıldığında; Balıkesir/Erdek (B: 0.13, Al: 2.08, Fe: 0.44, $\mathrm{Mn}: 0.10, \mathrm{Cl}^{-}: 287.06, \mathrm{NO}_{2}^{-}: 23.54, \mathrm{NO}_{3}: 179.41^{-}, \mathrm{Br}^{-}: 0.64$, $\left.\mathrm{SO}_{4}{ }^{-2}: 302.61 \mathrm{ppm}\right), \mathrm{Mersin} / \mathrm{Karaduvar}-\mathrm{Davultepe}(\mathrm{Mg}: 130.30, \mathrm{Al}: 0.24, \mathrm{As}: 0.02, \mathrm{Na}: 393.85, \mathrm{~K}: 12.06$, $\mathrm{Cl}:$ 712.83, $\mathrm{NO}_{2}^{-}: 1.85, \mathrm{NO}_{3}^{-}: 479.11, \mathrm{Br}^{-}: 1.48 \mathrm{ppm}$ ), Samsun/Merkez (B:0.2 , $\mathrm{Mg}^{-}: 53.36, \mathrm{NO}_{2}^{-}: 1.06$, $\mathrm{NO}_{3}{ }^{-}:$144.03, $\mathrm{Br}^{-}: 0.07 \mathrm{ppm}$ ) ve Diyarbakır/Merkez (B: $0.02, \mathrm{NO}_{2}{ }^{-}: 8.72 \mathrm{ppm}$ ) bölgelerinde bazı ağır metal ve anyon değerlerinin müsaade edilen sınır değerlerin üzerinde olduğu saptanmıştır. Özellikle anomali gösteren bu parametreleri içeren suların sürekli tüketimi zamanla çeşitli hastalıklara neden olabilmektedir. Bu nedenle özellikle kirlilik kaynağının (evsel atık, deniz suyu karışımı, formasyon kaynaklı vb.) araştırılarak gerekli önlemlerin alınması ve bu suların kontrollü olarak içilmesi önerilmektedir.

Anahtar Kelimeler: Su, Ağır metal, Anyon, Tıbbı Jeoloji, Anadolu

\section{Giriş}

$\mathrm{Su}$; canlıların biyolojik yaşamlarının ve özellikle insan faaliyetlerinin devamlılı̆̆ı açısından önemli bir gereksinimdir. İçerdiği elementler bakımından doku ve kemik sağlığ 1 için çok önemli olan su; kan dolaşımının gerçekleşebilmesi, vücudun zararlı maddelerini atabilmesi, iç zarlarının kurumadan görevini yapabilmesi için hayati önem taşır $[1,2,3,4,5]$.

Yeryüzünün \% 80'i sularla kaplı olmasına rağmen su kaynaklarının ancak \% 1'i kullanılabilir ve içilebilir özelliktedir. Dünya nüfusunun çok hızlı artışı, sanayi ve teknolojinin gelişmesi, ayrıca çevre bilincinin yeterince yerleşememesi veya yaygınlaşamaması gibi pek çok nedenler dünyada içilebilir su miktarının giderek azalmasına sebep olmaktadır. Ayrıca, içilebilir su kaynaklarının sorumsuzca kirletilmesi, geri dönüşümü olanaksız sorunların yaşanmasına zemin hazırlamaktadır $[6,7,8]$.

İnsan vücudunun \% 5' inin elementlerden oluştuğunun bilinmesi, ancak uzun süre bu \% 5' lik değerin önemsenmemesi nedeni ile son yıllarda özellikle vücudun dengede kalabilmesi için bazı elementlerin önemini daha da arttırmıştır. Özellikle de içme suyu olarak tüketilen suların kalitesindeki bozulmalar zamanla çeşitli hastalıklara yol açtığı, bu konu ile ilgili yapılan çalışmalarda da bu tür hastalıkların jeolojik birimler ile ilgili olduğunu ortaya çıkarmıştır. Bu nedenle içme suyu olarak tüketilen sularının belirli standartlara sahip olması gerekmektedir [5, 9, 10, 11, 12].

$\mathrm{Bu}$ çalışma ile de Anadolu'nun farklı bölgelerinde (Balıkesir/Erdek, Mersin/Karaduvar-Davultepe, Samsun/Merkez ve Diyarbakır/Merkez) tüketilen içme sularının ağır metal ve anyon içeriklerine göre içilebilirlik özellikleri araştırılmış ve tıbbi jeoloji açısından değerlendirilmiştir (Şekil 1).

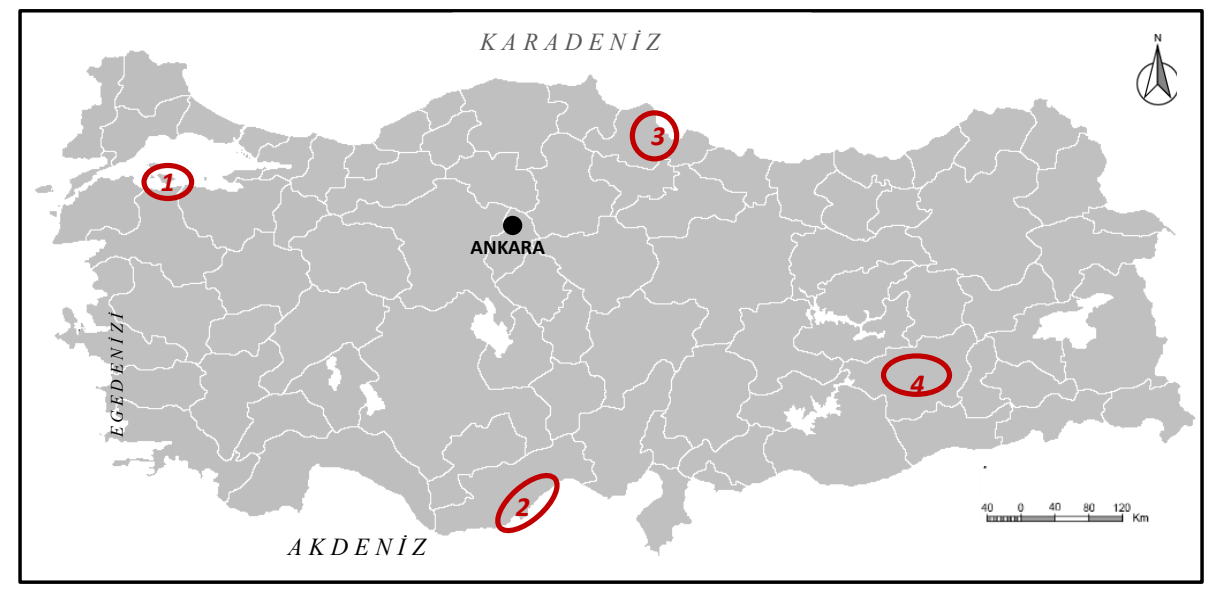

Şekil 1. Çalışma alanı yer bulduru haritası

(1. Balıkesir/Erdek 2.Mersin Karaduvar-Davultepe 3. Samsun/Merkez 4. Diyarbakır/Merkez) 


\section{Jeoloji}

Çalışma alanı olarak seçilen Anadolu'nun farklı bölgelerinde yer alan Balıkesir, Mersin, Samsun ve Diyarbakır bölgelerinin jeolojisi şöyle özetlenebilir;

\subsection{Ballkesir Bölgesinin Jeolojisi}

Üst Paleozoyik yaşl1, yer yer mercek ve bant şeklinde mermerler ve serpantinit kütleleri içeren metamorfik Fazlıkonağı Formasyonu temel birimi oluşturmaktadır. Bu birimi yine Üst Paleozoyik yaşlı granodiyorit ve granit türde bir sokulum olan Kapıdağ graniti kesmektedir. Daha üstte uyumsuz olarak Alt Triyas yaşlı çeşitli kırıntılı kayalar ve kireçtaşı bloklarından oluşan Karakaya Formasyonu; konglomera, kumtaşı, kumlu kireçtaşı ve kireçtaşı düzeylerinin oluşturduğu Orta- Üst Triyas yaşlı Çaltepe Formasyonu ise bu birimin üzerinde uyumsuz olarak yer almaktadır. Üst Jura-Alt Kretase yaşlı Akçakoyun Formasyonuna ait kireçtaşlarından sonra, yerleşme yaşı Üst Kretase olan ve birbirleriyle ilksel ilişkide olmayan çökel, metamorfik ve ofiyolit topluluğuna ait karmaşık bir formasyon olan Yayla melanjı gözlenir. Bölgede Tersiyer-Paleojen yaşlı granodiyorit ve granit türde Çataldağ ile Ilıca-Şamlı granitleri, Miyosen-Pliyosen yaşı karasal ortamda meydana gelmiş çökel kayalar, Miyosen- Pliyosen yaşlı volkanik kayalar; Kuvaterner ise, yüzlek birikintilerle temsil olunur (Şekil 2) [13, 14, 15, 16, 17, $18]$.

\subsection{Mersin Bölgesinin Jeolojisi}

Bölge, Alpin Orojenezine bağlı olarak gelişen Toros kuşağı içerisinde yer almaktadır [19] ve Toros kuşağının temel özelliklerini yansıtmakta olup bol kıvrımlı, kırıklı ve bindirmeli yapı sunmaktadır. Bu kuşağın temelini Paleozoik yaşlı metamorfizmaya uğramış Karahamzauşağı Formasyonu oluşturmaktadır. Bu birimin üzerine Üst Kretaese' de yerleşmiş olan okyanus tabanı serisi mafik ve ultramafik kayaçlar bindirmeyle gelmiştir [20]. Gildirli Formasyonu, Karaisalı Formasyonu, Güvenç Formasyonu ve Handere Formasyonu bölgede çökelmiş Tersiyer oluşuklarıdır. Bu birimlerin üzerine Kuvaterner birimleri olarak kaliş, alüvyon ve yamaç molozları gelmektedir (Şekil 2).

\subsection{Samsun Bölgesinin Jeolojisi}

Bölgenin temel birimini oluşturan Orta-Üst Eosen yaşlı Tekkeköy Formasyonu volkanik ve volkanotortul bir istif olup tabanda kumtaşı, marn ve tüfit ardalanması ile bazalt ve aglomeralardan oluşmuştur. Birim üzerine Üst Miyosen-Alt Pliyosen yaşlı volkanik çakıllardan oluşan bir taban konglomerası, marn ile kil ve jips ara bantlı kumtaşı, silttaşı ve çakıltaşı düzeylerinden oluşmuş İlyas Formasyonu gelmektedir. Karasamsun Formasyonu Alt Pliyosen yaşlı birim olup kumtaşı, silttaşı ve marn mercekleri içeren, yer yer iyi çimentolu konglomeralardan oluşmuştur. Bölgenin Kuvaterner yaşlı en geç birimlerini ise çakıl, çok ince kum ve siltlerden oluşmuş Güncel Taşkın Ovası Çökelleri ve kum, silt, kötü derecelenmiş denizel kavkılar içeren Alüvyon oluşturmaktadır (Şekil 2) [21].

\subsection{Diyarbakır Bölgesinin Jeolojisi}

Jeotektonik konum itibariyle Arabistan Platformu üzerinde yer alan bölge, jeolojik açıdan bu platformun tipik özelliklerini sergilemektedir. Güneyde Mardin yükselimi ve kuzeyde kıvrımlı kuşak ile Bitlis Sütur Zonu arasında kalan Diyarbakır Havzası, dört bir tarafindan platforma ait Eosen-Miyosen yaşlı karbonatlar ile kuşatılmıştır. Bu karbonatların üzerinde geniş yüzeylenmeler veren Alt Miyosen yaşlı filișler yer almaktadır. Pleyistosen'de bölgede özellikle Dicle vadisinin kuzey kesimlerinde, akarsu ortamlarında masif konglomera çökelimleri olmuştur. Güncel akarsu boylarında görülen alüvyonlar Holosen yaşlı en genç çökellerdir (Şekil 2) [22]. 
International Journal of Scientific and Technological Research ISSN 2422-8702 (Online), DOI: 10.7176/JSTR/5-5-13

Vol.5, No.5, 2019 www.iiste.org

IIII)

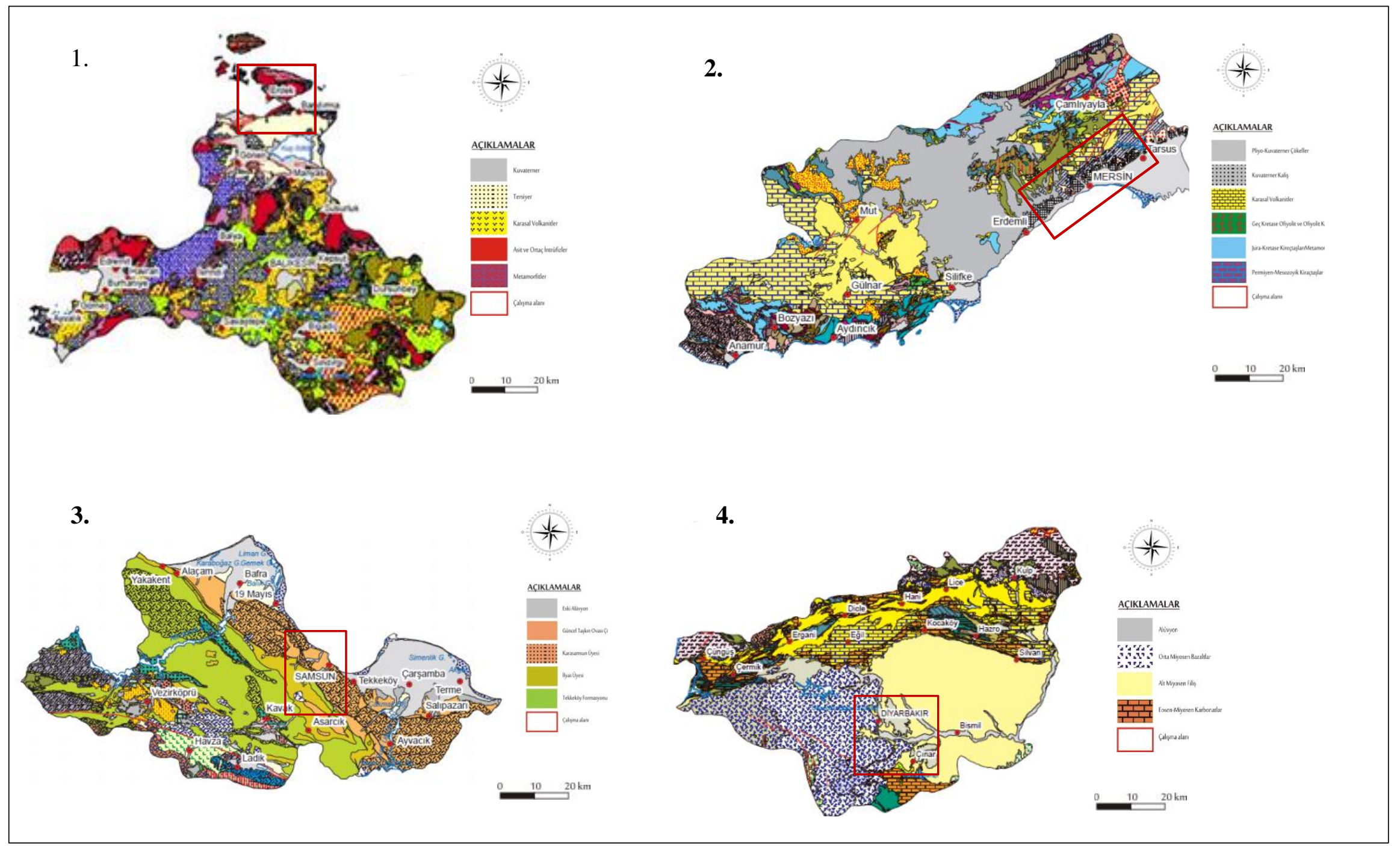

Şekil 2. Çalışma alanı jeoloji haritaları [23].

(1. Balıkesir/Erdek 2.Mersin Karaduvar-Davultepe 3. Samsun/Merkez 4. Diyarbakır/Merkez)

$122 \mid \mathrm{P}$ a g e

www.iiste.org 


\section{Materyal ve Yöntemler}

\subsection{Su Örneklerinin Kimyasal Analiz Yöntemleri}

Bu çalışmada; Balıkesir/Erdek, Mersin/Davultepe-Karaduvar, Samsun/Merkez ve Diyarbakır/Merkez bölgelerinde içme suyu olarak tüketilen su örneklerinin kimyasal ve fiziksel parametrelerini belirlemek ve içilebilirlik özelliklerinin ortaya konması için çalışma alanlarından sistematik olarak toplam 136 adet (87 şebeke, 40 kuyu, 9 şişe) su örneği alınmıştır (Şekil 3).

Su örneklerinin alımı sırasında 500 mililitrelik temiz ped şişeler üç kez örnek su alınarak çalkalanmış, daha sonra şişe doluncaya kadar birisi şahit örnek olmak üzere 2 şişe numune alımı gerçekleştirilmiştir. Alınan su örnekleri 100 cc'lik polietilen şişelere konulmuş ve pH' sı 2'ye düşürülene kadar suya \%1 oranında $\mathrm{HNO}_{3}$ ilave (sudaki organizmaların ağır metalleri parçalayarak kimyasal reaksiyon başlatmalarını engellemek için) edilmiştir [24]. Alınan 134 adet su örneğinin; pH ve elektrik iletkenliği değerleri arazide örnek alımı sırasında ölçülmüştür (YSI Professional Plus). Ağır metal ve anyon içerikleri ise Mersin Üniversitesi İleri Teknoloji Eğitim, Araştırma ve Uygulama Merkezinde (MEITAM) ICP-MS (Inductively Coupled Plasma - Mass Spectrometer) ve IC (İyon Kromatografisi) ile belirlenmiştir. 
International Journal of Scientific and Technological Research ISSN 2422-8702 (Online), DOI: 10.7176/JSTR/5-5-13

Vol.5, No.5, 2019 www.iiste.org

usish
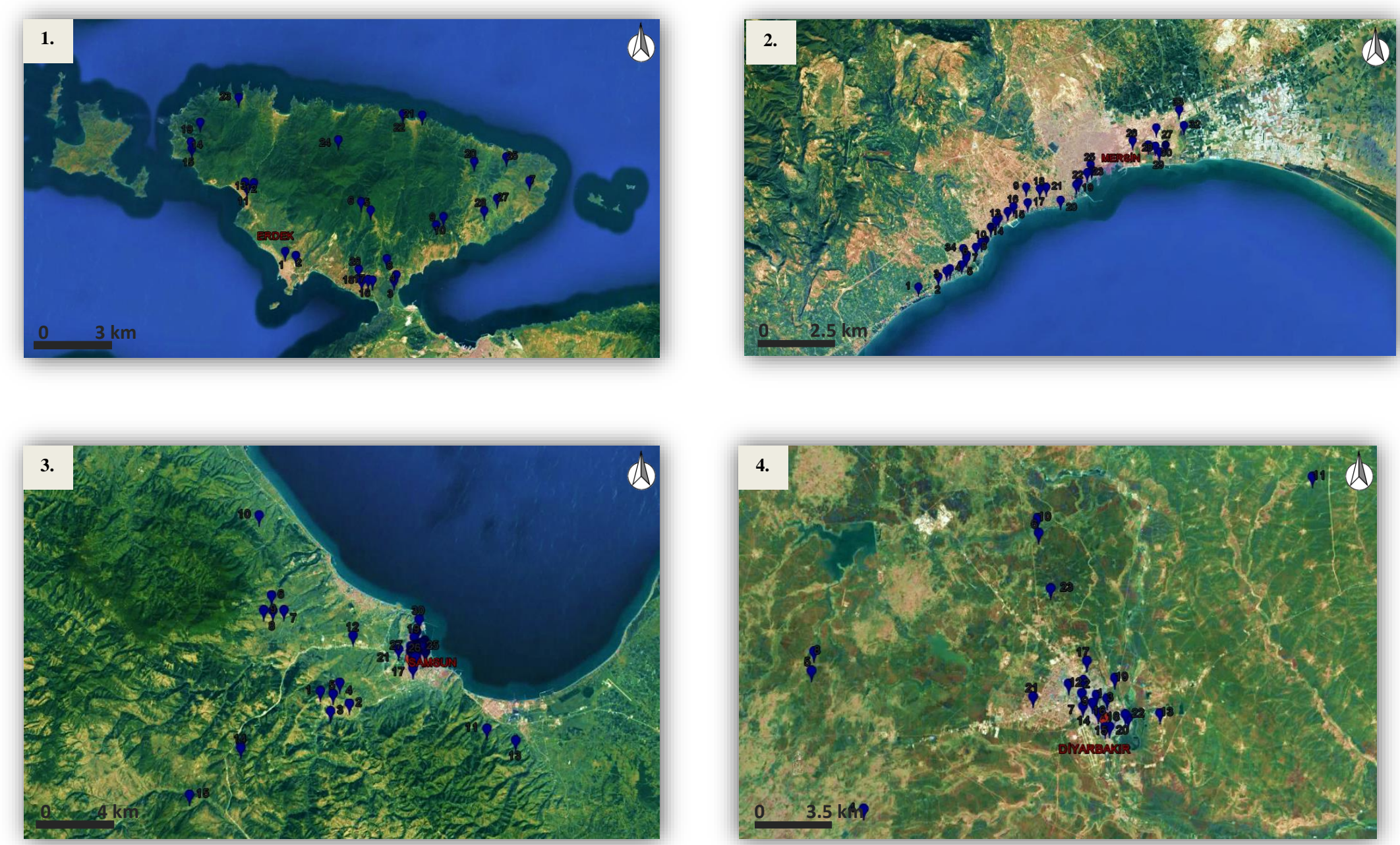

Şekil 3. Çalışma alanı örnekleme haritaları

(1. Balıkesir/Erdek 2.Mersin Karaduvar-Davultepe 3. Samsun/Merkez 4. Diyarbakır/Merkez)

124 | P a g e

www.iiste.org 


\section{Bulgular}

$\mathrm{Bu}$ çalı̧̧mada, incelenen su örneklerine ait element ve anyon içerikleri için minimum, maksimum, ortalama ve ortanca değerler ile TSE 266 [25], WHO (Dünya Sağlık Örgütü) [26] ve EPA (ABD Çevre Koruma Ajansi) [27] standartları Tablo 1 ve Tablo 2' de ppm olarak verilmiştir.

\subsection{Balıkesir/Erdek bölgesi su örneklerinin element ve anyon içerikleri}

Balıkesir/Erdek bölgesinden toplam 28 adet şebeke suyu örneği alınmıştır. Bu su örneklerinin element ve anyon içerikleri Tablo 1 ve 2 'de belirtilen standartlarla karşılaştırıldığında; $\mathrm{B}(0.13), \mathrm{Al}(2.08), \mathrm{NO}_{3}{ }^{-}$ (179.41) ve $\mathrm{Br}^{-}(0.64)$ içeriğinin tüm örneklerde; $\mathrm{Mn}(0.1), \mathrm{Fe}(0.44), \mathrm{Cl}^{-}(287.06), \mathrm{NO}_{2}^{-}$(23.54) ve $\mathrm{SO}_{4}^{-}$ 2 (302.61) içeriğinin ise bazı örneklerde belirtilen standart değerlerin üzerinde olduğu belirlenmiştir. Ayrica; $\mathrm{Cr}$ (0.003), Ni (0.004), Cu (0.01), Zn (0.06), As (0.003), Se (0.005), Cd (-), Ba (0.3), Pb (0), $\mathrm{Na}$ (114.9), $\mathrm{Mg}(20.91), \mathrm{K}(5.94), \mathrm{Ca}(68,23), \mathrm{F}^{-}$(0.43) ve $\mathrm{PO}_{4}^{-2}$ (1.64) içeriği de tüm örneklerde belirtilen standart değerler içerisindedir.

\subsection{Mersin/Karaduvar-Davultepe bölgesi su örneklerinin element ve anyon içerikleri}

Mersin/Karaduvar-Davultepe sahil şeridi boyunca toplam 34 adet kuyu suyu örneği alınmıştır. Bu su örneklerinin element ve anyon içerikleri Tablo 1 ve 2 'de belirtilen standartlarla karşılaştırıldığında; B (1.21), $\mathrm{Mg}$ (130.30), $\mathrm{Cl}^{-}$(712.83), $\mathrm{NO}_{3}^{-}$(479.11) ve $\mathrm{Br}^{-}$(1.48) içeriğinin tüm örneklerde; $\mathrm{Al}(0.24)$, As (0.02), $\mathrm{Na}(393.85)$ ve $\mathrm{K}(12.06)$ ve $\mathrm{NO}_{2}^{-}(1.85)$ içeriğinin ise bazı örneklerde standart değerlerin üzerinde olduğu belirlenmiştir. Ayrıca; $\mathrm{Cr}(0.009), \mathrm{Mn}(0.02), \mathrm{Fe}(0.07), \mathrm{Ni}(0.01), \mathrm{Cu}(0.01), \mathrm{Zn}(1.76)$, Se (0.009), $\mathrm{Cd}(D L), \mathrm{Ba}(0.22), \mathrm{Pb}(0.002), \mathrm{Ca}(128.80), \mathrm{F}^{-}(0.65), \mathrm{SO}_{4}^{-2}$ (228.50) ve $\mathrm{PO}_{4}^{-2}(0.15)$ içeriği de tüm örneklerde belirtilen standart değerler içerisindedir.

\subsection{Samsun/Merkez bölgesi su örneklerinin element ve anyon içerikleri}

Samsun/Merkez bölgesinden toplam 31adet şişe (9), kuyu (6) ve şebeke (16) suyu örneği alınmıştır. Bu su örneklerinin element ve anyon içerikleri Tablo 1 ve 2 'de belirtilen standartlarla karşılaştırıldığında; $\mathrm{B}(0.21)$ ve $\mathrm{Br}^{-}(0.07)$ içeriği tüm örneklerde; $\mathrm{Mg}(53.36), \mathrm{NO}_{2}^{-}(1.06)$ ve $\mathrm{NO}_{3}^{-}(144.03)$ içeriğinin ise bazı örneklerde standart değerlerin üzerinde olduğu belirlenmiştir. Ayrıca; $\mathrm{Al}(0.15), \mathrm{Cr}(0.002), \mathrm{Mn}(-)$, $\mathrm{Fe}(0.05), \mathrm{Ni}(0.003), \mathrm{Cu}(0.02), \mathrm{Zn}(0.12)$, As (0.005), Se (0.006), Cd (-), Ba (0.07), $\mathrm{Pb}(0.003), \mathrm{Na}$ (75.09), $\mathrm{K}$ (4.37), $\mathrm{Ca}$ (88.48), $\mathrm{F}^{-}(0.43), \mathrm{Cl}^{-}$(44.16), $\mathrm{Br}^{-}(0.07), \mathrm{SO}_{4}^{-2}$ (81.17) ve $\mathrm{PO}_{4}^{-2}(0.11)$ içeriği de tüm örneklerde belirtilen standart değerler içerisindedir.

\subsection{Diyarbakır/Merkez bölgesi su örneklerinin element ve anyon içerikleri}

Diyarbakır/Merkez bölgesinden toplam 43 adet şebeke suyu örneği alınmıştır. Bu su örneklerinin element ve anyon içerikleri Tablo 1 ve 2 'de belirtilen standartlarla karşılaştırıldığında; $\mathrm{B}(0.02)$ ve $\mathrm{NO}_{2}{ }^{-}(8.72)$ içeriğinin tüm örneklerde standart değerlerin üzerinde olduğu belirlenmiştir. $\mathrm{Al}(D L), \mathrm{Cr}(D L), \operatorname{Mn}(D L)$, $\mathrm{Fe}(D L), \mathrm{Ni}(0.002), \mathrm{Cu}(0.002), \mathrm{Zn}(0.62), \mathrm{As}(D L), \mathrm{Se}$ (0.007), $\mathrm{Cd}(D L), \mathrm{Ba}(0.024), \mathrm{Pb}(D L), \mathrm{Na}(9.91)$, $\mathrm{Mg}$ (1.33), $\mathrm{K}(15.09), \mathrm{Ca}(50.01), \mathrm{F}^{-}(0.14), \mathrm{Cl}^{-}(10.17), \mathrm{NO}_{3}^{-}(6.34), \mathrm{Br}^{-}(D L), \mathrm{SO}_{4}^{-2}$ (40.94) ve $\mathrm{PO}_{4}^{-2}$ $(D L)$ içeriği ise tüm örneklerde belirtilen standart değerler içerisindedir.

Ayrıca pH (6.5-9.5) ve E.İ. (2500>) değerlerinin tüm bölgelerde belirtilen standartlara uygun olduğu belirlenmiştir (Tablo 2).

\section{Sonuçlar ve Tartışmalar}

Çalışma bölgelerinden (Balıkesir, Mersin, Samsun ve Diyarbakır illerinin bazı bölgeleri) alınan su örnekleri üzerinde yapılan incelemeler sonucu elde edilen element içerikleri bölgeler açısından belirtilen standartlara [25, 26, 27] göre değerlendirildiğinde; Bor (B) elementinin tüm bölgelerde, Alüminyum (Al) elementinin Balıkesir/Erdek bölgesinde, Magnezyum (Mg) elementinin ise Mersin/Karaduvar-Davultepe 
bölgesinde anomali gösterdiği belirlenmiştir (Tablo 1, Şekil 4). Anyon içerikleri de aynı şekilde bölgelere göre değerlendirildiğinde; Bromür $\left(\mathrm{Br}^{-}\right)$anyonunun Balıkesir/Erdek, Mersin/Karaduvar-Davultepe ve Samsun/Merkez bölgelerinde, Nitrat $\left(\mathrm{NO}_{3}{ }^{-}\right)$anyonunun Balıkesir/Erdek ve Mersin/Karaduvar-Davultepe bölgelerinde, Nitrit $\left(\mathrm{NO}_{2}^{-}\right)$anyonunun Diyarbakır/Merkez bölgesinde, Klor $\left(\mathrm{Cl}^{-}\right)$anyonunun ise Mersin/Karaduvar-Davultepe bölgesinde belirtilen standart değerlerin üzerinde olduğu saptanmıştır (Tablo 2, Şekil 5).

Anomali gösteren bu elementlerin ve anyonların içme suyu olarak tüketilmesinin insan sağlığı açısından bazı toksik etkilere neden olması ve bu toksik etkilerin kaynağının belirlenerek gerekli önlemlerin alınması insan sağlığı açısından önemli olduğu için anomali gösteren $\mathrm{B}, \mathrm{Al}, \mathrm{Mg}$ elementleri ile $\mathrm{Br}^{-}, \mathrm{NO}_{3}{ }^{-}$ , $\mathrm{NO}_{2}{ }^{-}$ve $\mathrm{Cl}^{-}$anyonlarının insan sağ lı̆̆ açısından olumsuz etkileri ve bu olumsuz etkilerin kaynakları şu şekilde özetlenebilir;

Bor (B): İçme suyu kaynaklarındaki bor konsantrasyonu çevrenin jeolojik birimleri ve atık su deşarjlarına bağlı olarak değişiklik göstermektedir. Yapılan araştırmalara göre insan vücuduna alınan borun, \%90-95 oranı ilk 24 saatte değişikliğe uğramadan idrarla dışarı atılırken, çok az bir kısmı vücutta birikir ve yetişkinlerde baş ağrısı, kusma, ishal, heyecan, depresyon; çocuklarda ise daha çok havale, kanama, beyin zarı tahribi gibi etkiler rahatsızlıklar olarak görülür. Parmak uçlarında görülen pembe renk, bor ile zehirlenmeye işaret eden karakteristik görünümdür [28]. Ayrıca karaciğerde büyüme ve şişmeye, sinir sisteminden kaynaklanan benzeri sorunlara yol açtı̆̆ı da bilinmektedir [29].

Magnezyum (Mg): İçme sularında fazla miktarda bulunan magnezyum konsantrasyonu çoğunlukla yeraltı sularına magnezyumlu kalker, dolomit ve serpantizasyon sonucu açığa çıkan magnezyum karbonatın eritilmesiyle karışmakta ve suyun tadına acılık vermektedir. Ayrıca suyun sertliğine sebep olan iyonlardandır. Su sertliğinin az olduğu yerlerde kalp-damar hastalıklarının yaygınlığının arttığı tespit edilmiştir [30, 31]. Fakat bazı çalışmalarda da su sertliğinin kalp-damar hastalıklara karşı koruyucu etkisinin olmadığı bulunmuştur [32]. Sonuçta su sertliğinin sağlı̆̆a faydasıyla ilgili kılavuzlara girmiş bir öneri olmadığı gibi aşırısı, bağırsak rahatsızlıklarına neden olmaktadır [26, 33]. İnsan vücuduna fazla miktarda alınan magnezyum konsantrasyonu mide bulantısı, ishal, iştah kaybı, kas güçsüzlüğü, nefes almada güçlük, kan basıncında düşüklük, kalp atışında düzensizliğe neden olmaktadır. Ayrıca narkotik etki yapabildiği gibi gözlerde tahribata da neden olduğu yapılan çalışmalar ile belirlenmiştir.

Alüminyum (Al): İçme sularının fazla miktarda alüminyum konsantrasyonu içermesinin nedeni olarak su arıtımında aşırı alüminyum sülfat kullanılması, endüstriyel kirlenmeler veya toprağın yapısı ile bağlantılı olduğu düşünülebilir ve bu sular genellikle bulanık ve mavimsi bir görüntüdedir. İnsan sağlı̆̆1 açısından bu suların içme suyu olarak tüketilmesinin böbreklerde tahribata neden olduğu, akciğer ve sinir sistemini etkilediği yapılan çalışmalar ile belirlenmiştir [34]. Ayrıca, Alzheimer hastalığı yaptığına dair çalışmalar vardır [35]. ve alzheimer hastalarının beyinlerindeki alüminyum oranının arttığı belirtilmektedir [36].

Bromür $\left(\boldsymbol{B r}^{-}\right)$: İçme suyu olarak tüketilen suların kaynağında genellikle bromat bulunmazken bromür bulunabilmektedir. Bromür ise insan sağlığı açısından tehlikeli ya da zararlı bir anyon değildir. Ancak içme suyu olarak kullanılan suların kaynağında bromür varsa ve bu suların dezenfeksiyonunda ayrıca bazı organik maddelerin oksidasyonunda ozon kullanıldığında ozonlanma esnasında bromür bromata okside olmaktadır. Yani içme suyunda bromürün oksidasyonu sonucu bromat kirleticisi oluşturmaktadır. Bromürün ozonlanması ile bromat haline oksidasyonunu; ortamın $\mathrm{pH}$ '1, sıcaklığı, temas süresi ve organik madde miktarı gibi faktörleri etkilemektedir. Genel olarak reaksiyon;

$\mathrm{Br}^{-}+\mathrm{O}_{3} \rightarrow \mathrm{BrO}_{3}^{-}$ 
bu şekildedir. İçme suyu olarak tüketilen sularda belirtilen standart değerlerin üzerinde bromat içermesi mide bulantısı, kusma, ishal ve karın ağrısı gibi rahatsızlıklara neden olduğu, sinir sistemini, böbrekleri ve işitme sistemini ise olumsuz yönde etkilediği saptanmıştır. Uzun süreli maruz kalındığında ise kanser olma riskinin arttı̆̆

Nitrat $\left(\mathrm{NO}_{3}^{-}\right)$: İçme sularında bulunan nitratın asıl kaynağını organik maddeler, suni gübreler ve doğadaki bazı mineraller oluşturmaktadır. Yapılan çalışmalarda fazla miktarda nitrat içeren suların tüketimi, bebeklerde blue-baby denilen hastalığa neden olduğu belirtilmiştir [5, 35]. Fakat son yıllarda yapılan çalışmalar sonucunda içme suyundaki nitrat ile bebeklerde methemoglobinemi oluşması arasında direk bir bağlantı kurulmasının yanlış olacağı, nitratın bu hastalık oluşmasında etkili olabilecek birçok faktörden biri olabileceği vurgulanmıştır [37].

Nitrit $\left(\mathrm{NO}_{2}^{-}\right)$: İçme suyunda bulunan nitritin kaynağı olarak endüstriyel kirlenmeler, tarımda kullanılan gübre ayrıca güneş ışı̆̆ı ve bazı bakterilerin nitratlarının nitrite dönüşmesi olabilir. Organik maddenin yüksekliği nitrit ve nitrat derişimini arttırırken, ortamdaki bu gelişmelere bağlı olarak çözünmüş oksijen değeri de düşmektedir. Bu durumda oksijensizlikten boğulmaya ya da kan zehirlenmesine neden olabileceği belirtilmektedir [5, 38, 39].

Klor $\left(\boldsymbol{C l}^{-}\right.$): Suyun tadını (tuzluluk) bozan [5, 33] sürekli içimi halinde böbrek ve yüksek tansiyon problemlerine neden olan klorür iyonu, sodyum ile birlikte kanın bileşiminde bulunur ve kanın osmotik basıncını dengeler [31]. İçme sularında klorür iyonunun fazla miktarda bulunması deniz katkısı ya da endüstriyel bir kirlenmeden kaynaklı olabileceğini düşündürmekte ve $\mathrm{Cl}^{-}$iyonunun MersinKaraduvar/Davultepe bölgesinde anomali göstermesi bu düşünceyi desteklemektedir.

Balıkesir/Erdek bölgesinde bazı örneklerde yüksek değerlerde gözlenen Demir (Fe) elementi; jeolojik formasyonlardan ve demir içeren suni gübrelerden içme suyuna karışmaktadır. İçme sularındaki seviyelerinin $2 \mathrm{mg} / 1$ dozuna çıkması bile sağlığı etkilememekte, sadece suyun tadını ve görüntüsünü değiştirmektedir [26]. Ancak vücuda fazla miktarda alınmasında ise karaciğer yetersizliği, baş dönmesi ve mide ağrılarına sebep olabilmektedir [5, 30]. Mangan (Mn) elementi; jeolojik formasyonlardan ve mangan içeren suni gübrelerden içme suyuna karışmakta olup yüksek konsantrasyonlarda ise Alzheimer hastalığına yol açabilmektedir [30]. Sülfat $\left(\mathrm{SO}_{4}{ }^{-2}\right)$ anyonu; jips ve anhidrit kaynaklı içme suyuna karışmaktadır. Sülfür bileşikleri çeşitli reaksiyonlar sonunda oluşturdukları tat, koku, toksisite ve korozyon gibi problemleriyle önemli kirletici konumundadırlar. Sodyum sülfat ve magnezyum sülfat insanlarda müshil etkisi yaratmaktadır [5].

Mersin/Karaduvar-Davultepe bölgesinde ise bazı örneklerde yüksek değerlerde gözlenen Arsenik (As) elementi; içme sularına genelde sülfür minerallerinin bozulmasıyla ya da jeotermal alanlardan kaynaklı karışmaktadır [40]. Arsenikli suların sürekli kullanımında cilt hastalıkları özellikle de pigmentasyon değişiklikleri (melanosis) ve keratosis görülmekte az da olsa cilt kanseri oluşumu da bildirilmiştir. Ayrıca yapılan araştırmalar, kansere kadar ulaşabilen solunum yolu, karaciğer ve idrar yollarına ilişkin sağlık sorunları ile şeker hastalığı, kalp-damar ve sinir sistemi hastalıklarına da yol açtığını göstermiştir [41, 42]. Sodyum (Na) elementi; plajioklasların ayrışması, kil minerallerinin baz değişimi ve evaporitlerin bozunumu sonucu içme suyuna karışmaktadır. Sudaki sodyum miktarıyla hipertansiyon oluşumu arasında ispatlanmış bir ilişkiye rastlanmamıştır. Bununla birlikte verilen standart miktar olan 200mg/l üzeri konsantrasyonlarda suyun tadını değiştirmektedir [26]. Potasyum (K) elementi; içme suyunda potasyumlu minerallerin (Potasyumlu feldispatlar gibi) bozunumu, durayl potasyum minerallerinin oluşması (illit), iyon değişimi ve gözenek sularının yeraltı sularını beslemesine bağlı olarak bulunur [5]. Potasyum iyonunun kandaki eksikliğinde vücutta yorgunluk, kaslarda kramplar, kabızlık, kalpte ritim bozuklukları görülmektedir [31]. İçme suyundaki düşük ve yüksek konsantrasyonların insan sağlığına direk bir etkisinin bulunmadığı belirtilmiştir. 
International Journal of Scientific and Technological Research ISSN 2422-8702 (Online), DOI: 10.7176/JSTR/5-5-13

Vol.5, No.5, 2019 www.iiste.org

uish'

Tablo 1. Elementler için TSE 266, WHO, EPA İçme Suyu Standartları, maksimum ve minimum değerler

\begin{tabular}{|c|c|c|c|c|c|c|c|c|c|c|c|c|c|c|c|}
\hline \multirow{2}{*}{$\begin{array}{l}\text { Elementler } \\
(p p m)\end{array}$} & \multirow{3}{*}{$\begin{array}{l}\text { Türk } \\
\text { Standart } \\
\text { Enstitüsü } \\
\text { (TSE 266) } \\
{[25]}\end{array}$} & \multirow{3}{*}{$\begin{array}{l}\text { Dünya } \\
\text { Sağllk } \\
\text { Örgütü } \\
\text { (WHO) [26] }\end{array}$} & \multirow{3}{*}{$\begin{array}{l}\text { ABD Çevre } \\
\text { Koruma } \\
\text { Ajansı } \\
\text { (EPA) [27] }\end{array}$} & \multicolumn{2}{|c|}{$\begin{array}{l}\text { Balıkesir } \\
\text { Erdek }\end{array}$} & \multicolumn{2}{|c|}{$\begin{array}{c}\text { Mersin } \\
\text { Karaduvar-Davultepe }\end{array}$} & \multicolumn{6}{|c|}{$\begin{array}{l}\text { Samsun } \\
\text { Merkez }\end{array}$} & \multicolumn{2}{|c|}{$\begin{array}{c}\text { Diyarbakır } \\
\text { Merkez } \\
\text { Şebeke Suyu }\end{array}$} \\
\hline & & & & \multicolumn{2}{|c|}{ Şebeke Suyu } & Kuyu Suyu & & & & & & & & & \\
\hline & & & & $\begin{array}{l}\text { Min. } \\
\text { (ppm) }\end{array}$ & $\begin{array}{l}\text { Max. } \\
\text { (ppm) }\end{array}$ & $\begin{array}{l}\text { Min. } \\
\text { (ppm) }\end{array}$ & $\begin{array}{l}\text { Max. } \\
(\text { ppm })\end{array}$ & $\begin{array}{l}\text { Min. } \\
(\text { ppm })\end{array}$ & $\begin{array}{l}\text { Max. } \\
(p p m)\end{array}$ & $\begin{array}{l}\text { Min. } \\
(\text { ppm })\end{array}$ & $\begin{array}{l}\text { Max. } \\
\text { (ppm) }\end{array}$ & $\begin{array}{l}\text { Min. } \\
\text { (ppm) }\end{array}$ & $\begin{array}{l}\text { Max. } \\
(\text { ppm })\end{array}$ & $\begin{array}{l}\text { Min. } \\
(\text { ppm })\end{array}$ & $\begin{array}{l}\text { Max. } \\
(\text { ppm })\end{array}$ \\
\hline B & 0.001 & - & - & $\underline{0.003}$ & $\underline{0.130}$ & $\underline{0.040}$ & $\underline{1.210}$ & 0.004 & $\underline{0.210}$ & $\underline{0.023}$ & $\underline{0.090}$ & $\underline{0.015}$ & $\underline{0.016}$ & $\underline{0.013}$ & $\underline{0.022}$ \\
\hline Al & 0.2 & 0.2 & 0.2 & - & 2.080 & DL> & 0.240 & DL> & 0.004 & DL> & 0.003 & 0.089 & 0.151 & DL> & DL> \\
\hline $\mathrm{Cr}$ & 0.05 & 0.05 & 0.05 & 0.001 & 0.003 & DL> & 0.009 & DL> & 0.002 & DL> & DL> & DL> & DL> & DL> & DL> \\
\hline Mn & 0.05 & 0.05 & 0.1 & DL> & 0.100 & DL> & 0.020 & DL> & DL> & DL> & DL> & DL> & DL> & DL> & DL> \\
\hline $\mathbf{F e}$ & 0.2 & 0.2 & 0.3 & DL> & $\underline{0.440}$ & DL> & 0.070 & DL> & DL> & DL> & 0.010 & 0.025 & 0.052 & DL> & DL> \\
\hline $\mathbf{N i}$ & 0.02 & 0.02 & 0.02 & DL> & 0.004 & DL> & 0.010 & DL> & DL> & DL> & 0.002 & DL> & 0.003 & 0.001 & 0.002 \\
\hline $\mathbf{C u}$ & 2 & 2 & 2 & DL> & 0.010 & DL> & 0.010 & DL> & 0.002 & DL> & 0.020 & DL> & 0.005 & 0.001 & 0.002 \\
\hline Zn & 5 & 5 & 5 & DL> & 0.060 & DL> & 1.760 & DL> & 0.003 & DL> & 0.080 & DL> & 0.125 & 0.004 & 0.627 \\
\hline Se & 0.01 & 0.01 & 0.01 & 0.004 & 0.005 & 0.003 & 0.009 & 0.004 & 0.005 & 0.005 & 0.006 & 0.002 & 0.003 & 0.006 & 0.007 \\
\hline Cd & 0.005 & 0.005 & 0.005 & DL> & DL> & DL> & DL> & DL> & DL> & DL> & DL> & DL> & DL> & DL> & DL> \\
\hline $\mathbf{B a}$ & 0.3 & - & 1 & 0.002 & 0.300 & 0.020 & 0.220 & DL> & 0.010 & 0.001 & 0.070 & 0.058 & 0.061 & 0.003 & 0.024 \\
\hline $\mathbf{P b}$ & 0.01 & 0.01 & 0.01 & DL> & DL> & DL> & 0.002 & DL> & DL> & DL> & DL> & DL> & 0.003 & DL> & DL> \\
\hline $\mathrm{Na}$ & 200 & 200 & 200 & 9.770 & 114.90 & 10.350 & 393.850 & 1.800 & 14.550 & 18.710 & 75.090 & 7.750 & 8.070 & 0.225 & 9.908 \\
\hline $\mathbf{M g}$ & 50 & 50 & 50 & 0.340 & 20.910 & 16.060 & $\underline{130.300}$ & 2.350 & 27.010 & 15.230 & $\underline{53.360}$ & 8.580 & 8.870 & 0.138 & 1.334 \\
\hline $\mathbf{K}$ & 12 & - & - & 0.120 & 5.940 & 0.420 & $\underline{12.060}$ & 0.100 & 1.002 & 0.800 & 4.370 & 1.320 & 1.510 & 2.422 & 15.099 \\
\hline $\mathbf{C a}$ & 200 & - & - & 3.260 & 68.230 & 19.660 & 128.800 & 1.410 & 23.510 & 48.750 & 88.480 & 47.010 & 48.340 & 27.330 & 50.012 \\
\hline
\end{tabular}

*DL: Dedeksiyon Limiti

$128 \mid \mathrm{P}$ a g e

www.iiste.org 


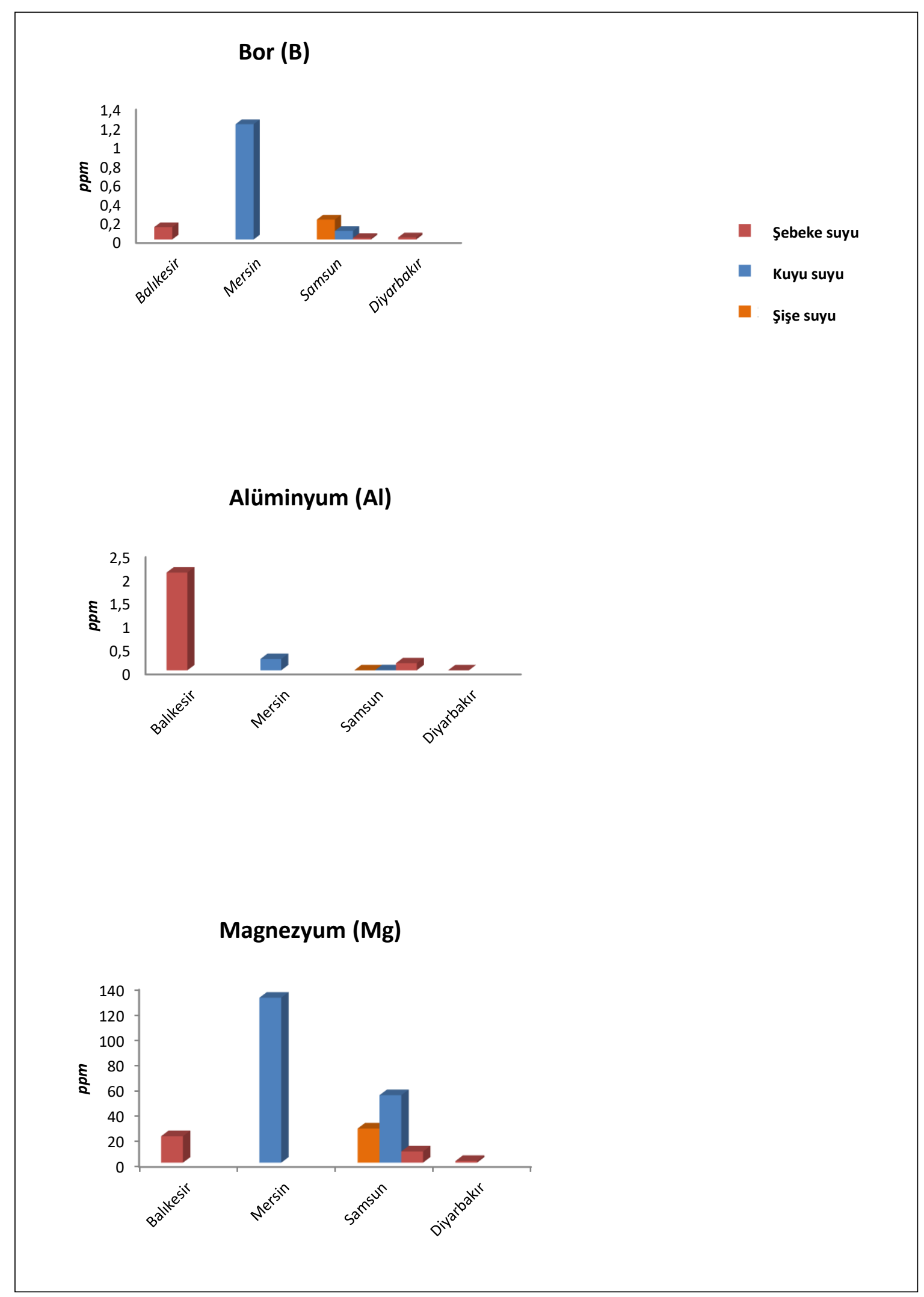

Şekil 4. Çalışma bölgelerinde (Balıkesir, Mersin, Samsun, Diyarbakır) anomali gösteren elementler 
International Journal of Scientific and Technological Research ISSN 2422-8702 (Online), DOI: 10.7176/JSTR/5-5-13

Vol.5, No.5, 2019 www.iiste.org

uisit

Tablo 2. Anyonlar için TSE 266, WHO, EPA İçme Suyu Standartları, maksimum ve minimum değerler

\begin{tabular}{|c|c|c|c|c|c|c|c|c|c|c|c|c|c|c|c|}
\hline \multirow{3}{*}{$\begin{array}{l}\text { Anyonlar } \\
\text { (ppm) }\end{array}$} & \multirow{3}{*}{$\begin{array}{l}\text { Türk } \\
\text { Standart } \\
\text { Enstitüsü } \\
\text { (TSE) [25] }\end{array}$} & \multirow{3}{*}{$\begin{array}{l}\text { Dünya } \\
\text { Sağllk } \\
\text { Örgütü } \\
\text { (WHO) } \\
{[26]}\end{array}$} & \multirow{3}{*}{$\begin{array}{l}\text { ABD } \\
\text { Çevre } \\
\text { Koruma } \\
\text { Ajansı } \\
\text { (EPA) } \\
{[27]}\end{array}$} & \multicolumn{2}{|c|}{$\begin{array}{c}\text { Balıkesir } \\
\text { Erdek }\end{array}$} & \multicolumn{2}{|c|}{$\begin{array}{c}\text { Mersin } \\
\text { Karaduvar-Davultepe }\end{array}$} & \multicolumn{6}{|c|}{$\begin{array}{l}\text { Samsun } \\
\text { Merkez }\end{array}$} & \multirow{2}{*}{\multicolumn{2}{|c|}{$\begin{array}{c}\begin{array}{c}\text { Diyarbakir } \\
\text { Merkez }\end{array} \\
\text { Sebeke Suyu } \\
\end{array}$}} \\
\hline & & & & \multicolumn{2}{|c|}{ Şebeke Suyu } & \multicolumn{2}{|c|}{ Kuyu Suyu } & \multicolumn{2}{|c|}{ Şişe Suyu } & \multicolumn{2}{|c|}{ Kuyu Suyu } & \multicolumn{2}{|c|}{ Şebeke Suyu } & & \\
\hline & & & & $\begin{array}{l}\text { Min. } \\
(\text { ppm })\end{array}$ & $\begin{array}{l}\text { Max. } \\
(\text { ppm })\end{array}$ & $\begin{array}{l}\text { Min. } \\
(\text { ppm })\end{array}$ & $\begin{array}{l}\text { Max. } \\
(\text { ppm })\end{array}$ & $\begin{array}{l}\text { Min. } \\
\text { (ppm) }\end{array}$ & $\begin{array}{l}\text { Max. } \\
(\text { ppm })\end{array}$ & $\begin{array}{l}\text { Min. } \\
(\text { ppm })\end{array}$ & $\begin{array}{l}\text { Max. } \\
(\text { ppm })\end{array}$ & $\begin{array}{l}\text { Min. } \\
\text { (ppm) }\end{array}$ & $\begin{array}{l}\text { Max. } \\
(\text { ppm })\end{array}$ & $\begin{array}{l}\text { Min. } \\
(\text { ppm })\end{array}$ & $\begin{array}{l}\text { Max. } \\
(\text { ppm) }\end{array}$ \\
\hline $\mathrm{F}^{-}$ & 1.50 & 1.50 & 1.50 & 0.04 & 0.43 & 0.08 & 0.65 & 0.03 & 0.16 & 0.23 & 0.43 & 0.03 & 0.20 & 0.06 & 0.14 \\
\hline $\mathrm{Cl}^{-}$ & 250 & 250 & 250 & 15.24 & 287.06 & $\begin{array}{ll}17.47 \\
\end{array}$ & $\underline{712.83}$ & 0.79 & 7.74 & 13.14 & 44.16 & 1.99 & 9.79 & 0.28 & 10.17 \\
\hline $\mathrm{NO}_{3}$ & 50 & 50 & 50 & 0.32 & 179.41 & 23.52 & $\underline{479.11}$ & 11.3 & 24.78 & 19.97 & $\underline{144.03}$ & 4.21 & 26.84 & 1.44 & 6.34 \\
\hline $\mathrm{Br}-$ & 0.01 & 0.01 & 0.02 & $\underline{0.03}$ & $\underline{0.64}$ & DL> & $\underline{1.48}$ & DL> & $\underline{0.03}$ & $\underline{0.04}$ & $\underline{0.07}$ & DL> & DL> & DL> & DL> \\
\hline $\mathrm{SO}_{4}^{-2}$ & 250 & 250 & 250 & $\underline{7.18}$ & $\underline{302.61}$ & 30.30 & 228.50 & 1.71 & 12.31 & 7.24 & 81.17 & 3.77 & 20.50 & 0.91 & 40.94 \\
\hline $\mathrm{PO}_{4}^{-3}$ & 5 & - & - & DL> & 1.64 & DL> & 0.15 & DL> & 0.10 & DL> & 0.11 & DL> & DL> & DL> & DL> \\
\hline $\mathrm{pH}$ & $6.5-9.5$ & $6.5-9.5$ & $6.5-8.5$ & 6.51 & 9.42 & 7.07 & 7.99 & 7.31 & 8.49 & 7.21 & 7.44 & 7.87 & 8.22 & 7.80 & 8.16 \\
\hline
\end{tabular}

*DL: Dedeksiyon Limiti 


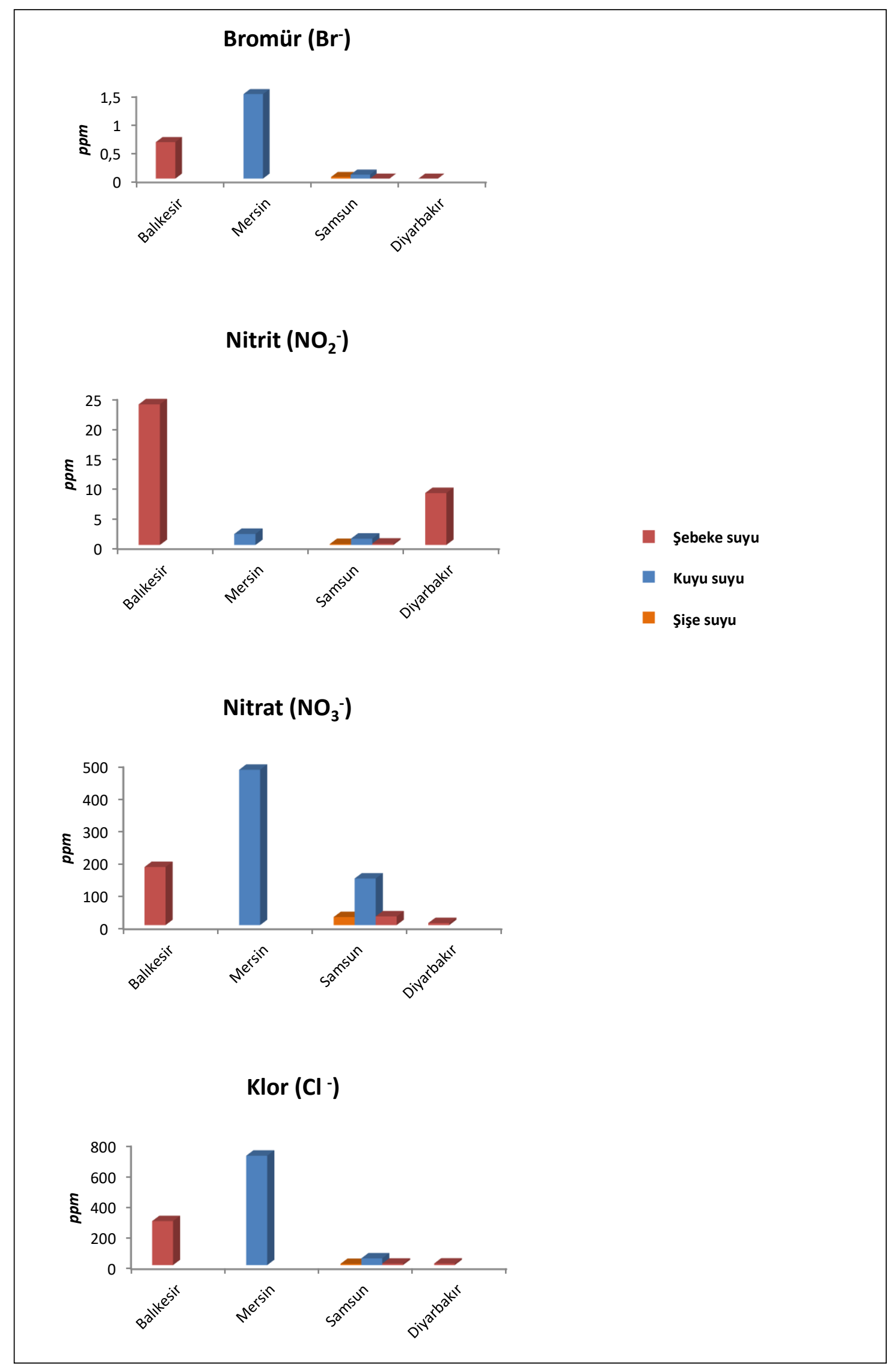

Şekil 5. Çalışma bölgelerinde (Balıkesir, Mersin, Samsun, Diyarbakır) anomali gösteren anyonlar 


\section{Sonuçlar}

Çalışma alanı olarak Anadolu'nun farklı bölgelerinde yer alan Balıkesir/Erdek, Mersin/KaraduvarDavultepe, Samsun/Merkez ve Diyarbakır/Merkez bölgeleri seçilmiş ve bu bölgelerde tüketilen içme sularının içilebilirlik özelliklerini araştırmak amacıyla toplam 134 adet su örneği alınmıştır. Alınan bu örneklerin element ve anyon içerikleri ICP-MS (B, Na, Mg, K, Ca, Cr, Mn, Ni, Cu, Zn, As, Cd, Ba, Pb, $\mathrm{Al}, \mathrm{Fe}, \mathrm{Se}, \mathrm{Mo})$ ve Iyon Kromatografisi $\left(\mathrm{F}^{-}, \mathrm{Cl}^{-}, \mathrm{NO}_{2}^{-}, \mathrm{NO}_{3}^{-}, \mathrm{Br}^{-}, \mathrm{SO}_{4}^{-2}, \mathrm{PO}_{4}^{-2}\right)$ ile analiz edilmiştir. $\mathrm{Bu}$ kimyasal analiz sonuçlarına göre minimum, maksimum, ortanca ve ortalama değerler hesaplanmış ve standartlara göre değerlendirilmiştir. Yapılan bu değerlendirmeler sonucu $\mathrm{B}, \mathrm{Mg}, \mathrm{Al}$ ile $\mathrm{Br}^{-}, \mathrm{NO}_{3}{ }^{-}, \mathrm{NO}_{2}{ }^{-}$ , $\mathrm{Cl}^{-}$içerikleri anomali değerler, bazı örnekler ise $\mathrm{Fe}, \mathrm{Mn}, \mathrm{As}, \mathrm{Na}, \mathrm{K}$ ile $\mathrm{SO}_{4}{ }^{-2}$ içerikleri açısından yüksek değerler göstermiştir. İncelenen su örneklerinde bazı elementlerin ve anyonların anomali göstermesi, bu suların içme suyu olarak kullanılmasının çeşitli hastalıklara (beyin zarı iltihabı, kusma, ishal, Alzheimer, tansiyon, cilt hastalıkları gibi) neden olacağından, kirliliğin nedenlerinin (evsel atık, deniz suyu karışımı, jeolojik formasyon kaynaklı vb.) araştırılarak gerekli önlemlerin alınması ve bu suların kontrollü olarak içilmesi önerilebilir. Ayrıca, içme suyu olarak tüketilen sulardaki element içeriklerinin, insan vücudunda yeterli miktarda alınmasını sağlamak amacıyla bölgede tüketilen şişe sularının anomali gösteren element ve anyon içerikleri açısından mümkünse daha düşük düzeyde olanların tüketilmesinin tercih edilmesinin yanında şişe sularının belli zamanlarda değiştirilmesi olası zararlı etkileri azaltacaktır. Ayrıca, şişe sularının üzerinde bünyesindeki element ve anyon içeriklerinin standartlarının da yer alması önerilebilir.

\section{Teşekkür}

$\mathrm{Bu}$ çalışmada incelenen su örneklerinin element içerikleri ve anyon düzeyleri Mersin Üniversitesi İleri Teknoloji Eğitim, Araştırma ve Uygulama Merkezi (MEITAMM) tarafından desteklenmiştir. Yazarlar desteklerinden dolayı MEİTAM başta olmak üzere laboratuvar çalışmalarında Dr. Öğr. Üyesi Mehmet Ali KURT' a, arazi çalışmalarında yardımlarından dolayı Jeo. Yük. Müh. Erkan DEMİR' e teşekkürlerini sunarlar.

\section{Kaynaklar}

1. Baysal, A. (1989). Genel Beslenme Bilgisi, Hatipoğlu Yayınevi, Ankara.

2. Himes, J.H. (1991). Anthropometrics Assessment of Nutritional Status, John Wiley \& Sons, New York, A.B.D.

3. Benjamin, C.L., Garman, G.R. \& Fuston, J.H. (1997). Human Biology, WCB/Mc Graw-Hill Companies, New York, A.B.D.

4. Akın, G., Güleç, E., Sağır, M., Gültekin, T. ve Bektaş, Y. (2005). Yaşlanma ve yaşlanmayı geciktiren çevresel etmenler”. III. Ulusal Yaşlılık Kongresi, İzmir, 127-137, 16-19 Kasım.

5. Atabey, E. (2005). Tıbbi Jeoloji, TMMOB Jeoloji Mühendisleri Odası Yayınları, Ankara, 134.

6. Atalık, A. (2006). Küresel ısınmanın su kaynakları ve tarım üzerine etkileri, Bilim ve Ütopya, 20: 18-21.

7. Dağlı, H. (2005). İçme suyu kalitesi ve insan sağlığına etkileri; bizim iller, İller Bankası Aylık Yayın Organı, 3: 16-21.

8. Haviland, W.A. (2002). Kültürel Antropoloji (Çev: Hüsamettin İnaç, Seda Çiftçi), Kaktüs Yayınlar1, Sosyoloji Serisi: 3, İstanbul, 143. 
9. Çakır, A., Özdemir, Z., Demir, E. ve Coşkun Önal, B. (2015). Balıkesir/Erdek bölgesinde tüketilen içme sularının tıbbi jeoloji açısından değerlendirilmesi, 2. Uluslararası Katılımlı Tıbbi Jeoloji Sempozyumu, TMMOB Jeoloji Mühendisleri Odası, Konya/Türkiye, 71-72, 12-15 Kasım.

10. Demir, Y., Satış, İ., Özdemir, Z., Coşkun Önal, B., Demir, E. ve Kurt, M. (2016). Samsun/Merkez bölgesinde içme suyu olarak tüketilen şişe, kuyu ve şebeke sularının tıbbi jeoloji açısından değerlendirilmesi, 69. Türkiye Jeoloji Kurultayı Bildiri Özleri Kitabı, MTA Kültür ve Kongre Merkezi, Ankara, 60-61, 11-15 Nisan.

11. Demir, A.F., Özdemir, Z., Coşkun Önal, B. ve Demir, E. (2016). Karaduvar-Davultepe (Mersin) kıyı şeridi boyunca kuyu sularının içilebilirlik özelliklerinin araştırılması, Uluslararası Katılımlı 7. Jeokimya Sempozyumu, Antalya/Türkiye, 154-155, 16-18 Mayıs.

12. Karademir, G., Özdemir, Z. ve Coşkun Önal, B. (2017). Diyarbakır İli Merkezinde İçme Suyu Olarak tüketilen Suların İçilebilirlik Özelliklerinin Araştırılması, 2nd International Mediterranean Science and Engineering Congress (IMSEC 2017), Adana/Türkiye, 25-27 Ekim.

13. Stanley, D.J. \& Blanfipied, C. (1980). Late Quaternary water exchange between the eastern Mediterranean and Black Sea, Nature, 285: 537-541.

14. Erol, O. ve Çetin, O. (1995). Marmara Denizi'nin Geç Miyosen-Holosen'deki evrimi; İzmit Körfezi Kuvaterner istifi, Kocaeli Valiliği Çevre Koruma Vakfi, Kocaeli, 314-341.

15. Meriç, E., Yanko, V., Avşar, N., Nazik, A. ve Koral, H. (1995). On the Marine interaction between the Mediterranean sea and the sea of Marmara during Quaternary time, Quaternary Sequence in the Gulf of İzmit, Kocaeli Valiliği Çevre Koruma Vakfi, Kocaeli, 285-293.

16. Smith, A.D., Taymaz, T., Oktay, F., Yüce, H., Alpar, B., Jackon, J. A., Kara, S. \& Şimşek, M. (1995). High-resolution seismic profiling in the sea of Marmara (North-west TURKEY); Late Quaternary sedimentation and sea-level changes, Geol. Soc. America Bull. 107/8, 923-936.

17. Ergin, M., Kazanc1, N., Varol, B. ve İleri, Ö. (1997b). Karadenizli L., Sea-level changes and related depositional environments on the southern Marmara Shelf, Mar. Geology, 140:391-403.

18. Görür, N., Çağatay, M.N., Sakınç, M., Sümengen, M., Şentürk, K., Yaltırak, C. ve Tehalpalyga, A. (1997). Origin of the Sea of Marmara as Deduced from Neogene to Quaternary Paleogeographic Evolution of its frame, Int. Geol. Rew., 39: 342-352.

19. Ketin, İ. (1983). Türkiye Jeolojisine Genel Bir Bakış, İstanbul Teknik Üniversitesi Matbaası, İstanbul, 595.

20. İşler, F. (1989). Fındıkpınarı ve Yöresi (Mersin) Ofiyolitlerinin Jeolojisi ve Petrografisi, Çukurova Üniversitesi Mühendislik Dergisi, Seri A Yer Bilimleri, c 6-7, s 1-2.

21. Öztekeşin, K. (2008). Samsun Kenti (Büyükşehir Belediyesi) İçme Suyu Potansiyeli, TMMOB Samsun Kent Sempozyumu, Samsun, 27-29 Kasim.

22. Çağdaş, F., Eminoğlu, M. ve Yalçınkaya H. (2009). Diyarbakır'ın İmara Esas Jeolojik Durumu, TMMOB Diyarbakır Kent Sempozyumu, Diyarbakır, 24-26 Nisan.

23. MTA, (2009). Genel Müdürlüğü, Türkiye Jeoloji Haritası, Ankara.

24. Sağdıç, A. (2003). Su Örneği Alma Tekniği, TTB Sürekli Tıp Eğitimi Dergisi, 12 (8), 310-312.

25. TSE 266, (2005). İnsani tüketim amaçlı sular, Türk İçme Suyu Standartları TS 266 sayılı standart -Türk Standartları Enstitüsü, Ankara. 
26. WHO, (2006). World Health Organization, Guidelines for drinking-water quality, third edition, Geneva, 221-459.

27. USEPA, (1999). National Primary Drinking Water Regulations, Available at http:/www.epa.gov/OGWD/hfacts.html.

28. Demirtaş, A. (2010). Bor'un İnsan Beslenmesi ve Sağlığı Açısından Önemi, Atatürk Üniversitesi Ziraat Fakültesi Dergisi, 41 (1), 75-80.

29. Cantürk, M. (2002). TÜBİTAK Bilim ve Teknik Dergisi.

30. Finkelman, R.B., Skinner, H.C.W., Plumlee, G.S. \& Bunnell, JE. (2001). Medical geology, Geotimes, 20-23.

31. Selinus, O., Alloway, B., Centeno, J.A., Finkelman, R.B., Fuge, R., Lindh, U. \& Smedley, P. (2005). Medical Geology, Elsevier, 115-594.

32. Morris, R.W., Walker, M., Lennon, L.T., Shaper, A.G. \& Whincup, P.H. (2008). Hard drinking water does not protect against cardiovascular disease: new evidence from the British Regional Heart Study, Eur J Cardiovasc Prev Rehabil, 15(2), 185-189.

33. Erguvanlı, K. ve Yüzer, E. (1987). Yeraltı suları Jeolojisi, İstanbul Teknik Üniversitesi Yayınları, İstanbul, 234-268.

34. Nordberg, M. \& Cherian, M.G. (2005). Biological responses of elements, Essentials of Medical Geology, Elsevier, Amsterdam, 179-200.

35. Akpınar, K. (2005). Dünyada ve Türkiye'de Suyun Kullanımı ve Geleceğimiz için Önemi, Sağlık Bakanlığı Temel Sağlık Hizmetleri Genel Müdürlüğü Hizmet içi Eğitimi, Yalova, 6.

36. Dissanayake, C.B. \& Chandrajith, R. (1999). Medical geochemistry of tropical environments , Earth Science Reviews, 47, 219-258.

37. Fewtrell, L. (2004). Drinking water nitrate, methemoglobinemia and global burden of disease: a discussion, Environ Health Perspect, 112(14), 1371-4.

38. Baltacı, F. (2000). Su Analiz Metotları, Türkiye Cumhuriyeti Enerji ve Tabii Kaynaklar Bakanlığı, Devlet Su İşleri Genel Müdürlüğü İçme suyu ve Kanalizasyon Dairesi Başkanlığ1, Ankara.

39. Egemen, Ö. (2006). Su Kalitesi, Ege Üniversitesi Yayınları, İzmir.

40. Smedley, P. (2001). Arsenic in Goundwater, 17-27.

41. Tchounwou, P.B., Centeno, J.A. \& Patlolla, A.K. (2004). Arsenic toxicity, mutagenesis and carcinogenesis a health risk assesment and management approach, Molecular and Cellular Biochemistry, 255: 47-55.

42. Tchounwou, P.B., Patlolla, A.K. \& Centeno, J.A. (2003). Carcinogenic and systemic health effects associated with arsenic exposure a critical review, Toxicology and Pathology, 31: 575588. 